http://jmscr.igmpublication.org/home/

ISSN (e)-2347-176x ISSN (p) 2455-0450

crossref DOI: https://dx.doi.org/10.18535/jmscr/v8i6.33

Journal Of Medical Science And Clinical Research

\title{
Clinical Outcome of Vacuum Assisted Closure Device in Healing of Complex Orthopaedic Wounds
}

\author{
Authors \\ Dr Mac Antony Michael ${ }^{1}$, Dr Jagajeev. JR ${ }^{2} *$, Dr Sabarisree $\mathbf{M}^{3}$ \\ ${ }^{1}$ Senior Resident in Orthopaedics, Government Medical College, Thiruvananthapuram \\ ${ }^{2}$ Addl. Professor, Dept. of Orthopaedics, Government Medical College, Thiruvananthapuram \\ ${ }^{3}$ Additional Professor in Orthopaedics, Government Medical College, Thiruvananthapuram \\ *Corresponding Author \\ Dr Jagajeev. JR
}

Addl. Professor, Dept. of Orthopaedics, Government Medical College, Thiruvananthapuram, India

\begin{abstract}
Background: Vacuum assisted wound healing is a recent innovation and proven technique that results in faster and better healing of wounds based on the application of negative suction pressure.

Objectives: To determine the clinical outcome of vacuum assisted closure device in healing of complex orthopedic wounds.

Methods: In this case series , a prospective longitudinal study was conducted on 56 patients with complex orthopedic wounds by negative pressure therapy in the form of vacuum assisted closure using low resources

Results: Evaluation done based on the changes in the wound surface areas and wound bed scores with each round of application of vacuum assisted closure device (maximum of 3).Reduction in wound surface area was $11.5 \%$ at the end of the treatment with $p=0.000$. Wound scoring on an average $68.4 \%$ at the end of treatment with VAC device with $P=0.000$.

Conclusion: Vacuum assisted closure device significantly and effectively improves wound healing and is especially useful in low resource setting.
\end{abstract}

\section{Introduction}

Vacuum assisted closure (VAC), also known as negative pressure wound therapy or micro deformational wound therapy, has brought a significant revolution in wound care in the past 20 years. The technique was pioneered by Louis Argenta and Dr. Michael morykwas in 1993.

The underlying principle of this technique is of removal of blood and serous fluid from the wound site by application of topical negative pressure. This will be done by applying a piece of autoclaved sponge foam and a drain over the surface of the wound after debridement and is fully covered over by a sterile plastic adherent membrane, securing it to skin margin and the drain is given connection to an electric vacuum creating unit. The standardized negative pressure applied is around $-125 \mathrm{~mm}$ of $\mathrm{Hg}$. There are other mechanisms of action of VAC as well such as increased stimulation of granulation tissue formation and angiogenesis that results in increased blood flow to wound bed. The main 
advantages of the VAC therapy are acceleration of wound healing, Reduction in the frequency in change of wound dressing, faster granulation of wound bed promoting contracture of wound edges, minimize wound contamination and to decrease total duration of hospital stay.

\section{Review of Literature}

For over a century, clinicians have applied suction to infections and all types of wounds: chronic, post-surgical and non traumatic. These events were first described in Biers hyperemic treatment in 1908.

Argenta and Morykwas researched wound healing with NPWT (Negative pressure wound therapy in full thickness wounds in swine. They demonstrated increased blood flow with application of $125 \mathrm{~mm}$ of $\mathrm{Hg}$ sub atmospheric pressure. They also observed decreased bacterial count and increased flap survival.

An animal model studied by Fabian et al revealed that wounds managed with negative NPWT demonstrated significantly smaller mean tissue gap and a greater mean peak granulation tissue compared to control wounds.

Jacoba et al studied rodent models to find out whether NPWT promotes granulation tissue formation and healing.

Early studies suggested that NPWT could reduce bacterial wound load. Weed et al provided a clinical retrospective report on effects of NPWT on bacterial load in 25 patients.

A randomized trial by Moues et al concluded that there was significantly more staphylococcus aureus and significantly less non fermentative gram- negative bacilli in NPWT treated wound.

Wackenfors et al used laser Doppler to measure microvascular blood flow in inguinal wounds of pigs during NPWT application. They observed that soft and dense tissues react differently to NPWT and that a lower sub atmospheric pressure during treatment may be more beneficial for soft tissue (-75 mg for soft tissue as opposed to -100 $\mathrm{mg}$ for dense tissue.)
Ichioka et al examined effects of VAC on blood flow in the wound bed, using a microscope video-computer system, at varying sub atmospheric pressures. They found that wound bed circulation was significantly improved with $125 \mathrm{~mm}$ of $\mathrm{Hg}$.

Kilpadi et al used a swine model to study the effects of VAC /NPWT on inflammatory cytokine levels. They observed a significantly earlier and greater peak of IL-10 and maintenance levels of IL-6 in the NPWT-treated wounds compared to the control wounds.

Saxena et al used computer based invitro model to study the effects of NPWT on micro deformation of cells. The observers hypothesize that tissue deformation caused by NPWT causes individual cells to stretch, which there by enhances cellular proliferation in the wound micro environment.

\section{Materials and Methods}

Complex wounds are wounds that involve multiple tissues and these often develop after devastating injuries. The effects of vacuum assisted closure device versus hat of conventional methods will be evaluated by measuring the following parameters.

1) Reduction of surface area of wound

2) Quality of wound healing assessed by Wound bed score.

Total of 56 patients were included in this study.

\section{Inclusion Criteria}

1) Trauma with exposed bone and tendon.

2) Fasciotomy wounds.

3) Open fractures with significantly large wounds and skin loss.

4) Dehisced wound

5) Infected non healing wound.

\section{Exclusion Criteria}

1) Donor sites for large grafts

2) Unexplored fistulae

3) Non co-operative and non- consenting patients

4) Wounds with exposed vessels or other vital structures 
5) Malignancy in wound

6) Patients currently on anticoagulants

7) Untreated osteomyelitis within vicinity of wound.

The study was for a period of one year from September 2016 to August 2017

\section{Outcome Variables}

Quality wound healing assessed by wound bed score.

Reduction in surface area of wound.

\section{Procedure}

After thorough debridement and hemostasis wound surface area is measured by copying its imprint over sterile plastic sheet on a graph paper and reading is recorded in $\mathrm{cm} 2$. Wound swab taken for culture and sensitivity. Wound is covered with bactigrass. A suction catheter / Ryles tube with sufficient fenestrations is placed inside the autoclaved sponge. This is then placed over the bactigrass. The whole wound area is sealed in an air tight manner with opsite /sterile polyethylene cover. Negative pressure applied using electrical suction machine at a range from $-75 \mathrm{~mm}$ of $\mathrm{Hg}$ to
$-200 \mathrm{~mm}$ of $\mathrm{Hg}$ for a period of 10 minutes every hour. VAC device changed at 42 to 72 hrs. Outcome variables assessed and exudate specimen sent of culture. Vacuum dressing was not continued beyond the 10th day in any of the cases.

\section{Observations}

Out of the 56 patients 50 were males and 6 were females. The youngest patient selected for the study was eleven years old and the oldest was 80 years old. Wound infection was present before application of VAC device in 4 of the patients. Of the remaining 52 patients, 49 were treated with VAC because they had chronic long term wounds that had not healed sufficiently to become closure by secondary or tertiary intention or grafting or flap. Among the 4 patients who presented with wound infection, all were post -operative cases that presented with wound dehiscence or wound site infection.7patients included in the study were found to be persons who smoked on a daily basis. 8 out of 56 patients were also found to be individuals who consumed alcohol on a daily basis.

\begin{tabular}{|c|c|c|c|c|c|c|}
\hline \multicolumn{7}{|c|}{ Wound Bed Score } \\
\hline & \multicolumn{2}{|c|}{ Scores of 0} & \multicolumn{2}{|c|}{ Scores of 1} & \multicolumn{2}{|c|}{ Scores of 2} \\
\hline Black Eschar & $b \rightarrow \square$ & 0 & $b \rightarrow \infty$ & 1 & $\infty$ & 2 \\
\hline Eczema/Dermatitis & Sermis: & 0 & topese & 1 & 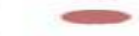 & 2 \\
\hline Depth & $\square$ & 0 & 25 & 1 & & 2 \\
\hline $\begin{array}{l}\text { Scarring } \\
\text { (fibrosis/callus) }\end{array}$ & 0 & 0 & & 1 & $\infty$ & 2 \\
\hline Color of wound bed & $\Longleftrightarrow$ & 0 & & 1 & & 2 \\
\hline Oedemarswelling & $1 \cdot 1$ & 0 & & 10 & - & 2 \\
\hline $\begin{array}{l}\text { Resurfacing } \\
\text { epithellum }\end{array}$ & $\longrightarrow \rightarrow \infty \square$ & 0 & $\longrightarrow \rightarrow \infty$ & 1 & $\rightarrow \rightarrow$ & 2 \\
\hline Exudate Amount & 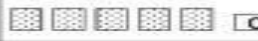 & 0 & 橉 图 图 & 1 & 溻 & 2 \\
\hline $\begin{array}{l}\text { Add scores for } \rightarrow \\
\text { each column }\end{array}$ & & & & & & \\
\hline TOTAL SCORE & & & & & & \\
\hline
\end{tabular}

\section{Results}

Serial documentation of changes in wound surface area and in the overall healing of the wound as evidenced by the changes in the wound bed score are recorded. The swab returned positive for infection in 6 patients. All these became negative for infection on subsequent application of VAC.
Finally after completion of all rounds of VAC device application the wound were then taken up for split thickness graft or flap cover (4 Cases). Graft taken up was $90 \%$ in 48 wounds while remaining 4 wounds showed an uptake in excess of $75 \%$. Following bar diagrams demonstrate outcome variables before and after VAC device. 

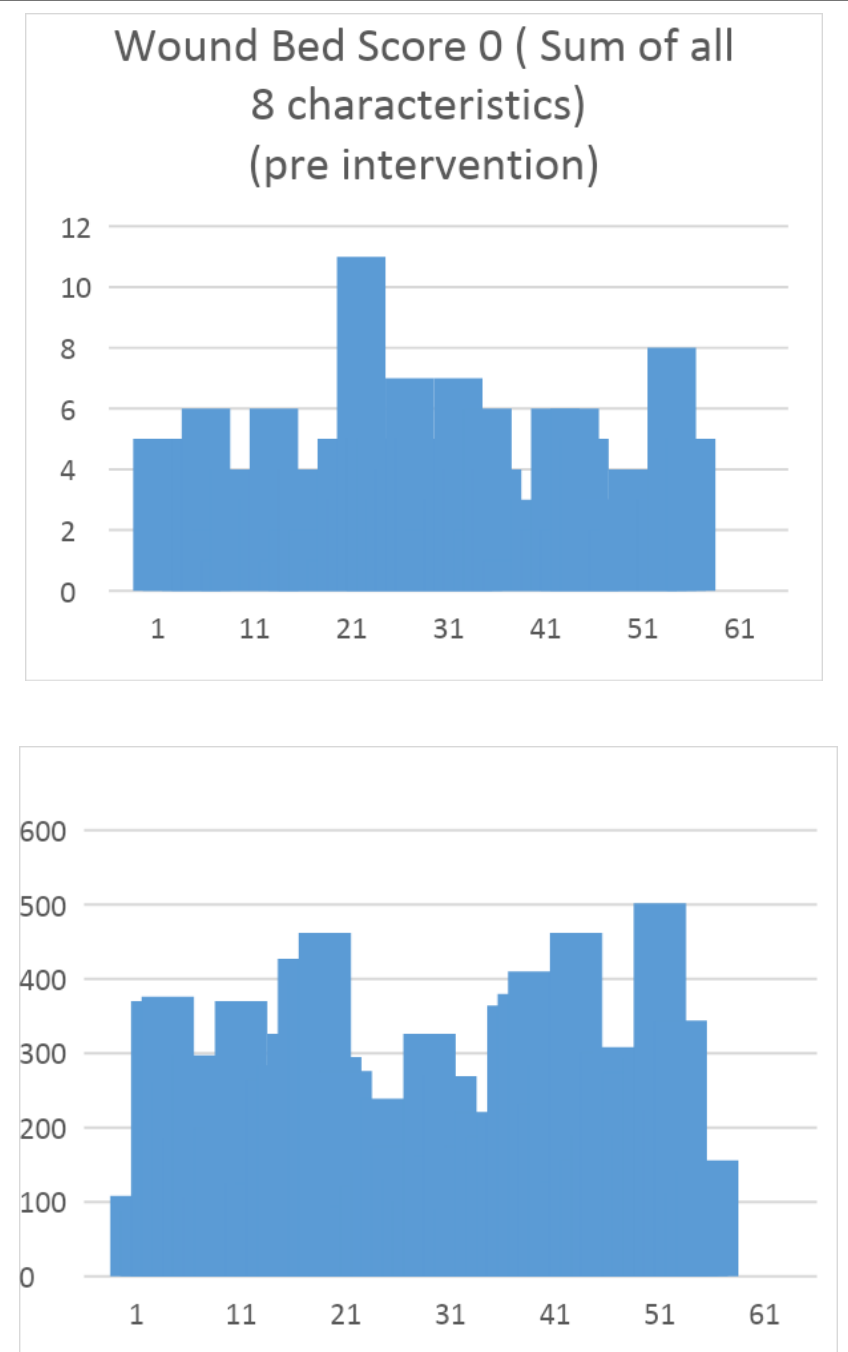

\section{Discussion}

Repeated measures ANOVA was found to be the best statistical tool available to meaningfully analyse the obtained set of data and it was therefore used in the interpretation of this data. To further analyse, we have used Repeated measure ANOVA and Wilkins Lambda test which is probability distribution used in multivariate hypothesis testing. The wounds appear to have shrunken in size with sequential application of VAC dressing. There is significant increase in the wound bed score over time suggesting that treatment with VAC device helped to improve wound healing significantly. Application of VAC was also found to decrease the time taken till wound was ready to be closed as well as suggesting a higher rate of graft or flap uptake.
Wound bed score 3 (sum of all 8 characteristics)

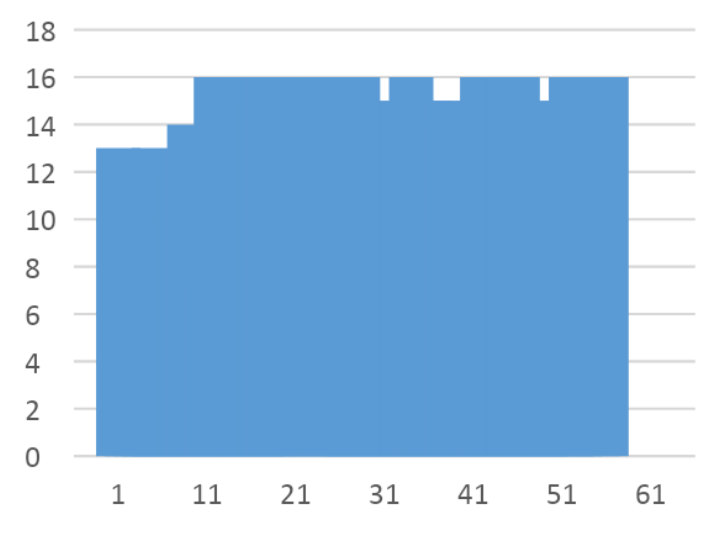

Surface Area 3(cm2)

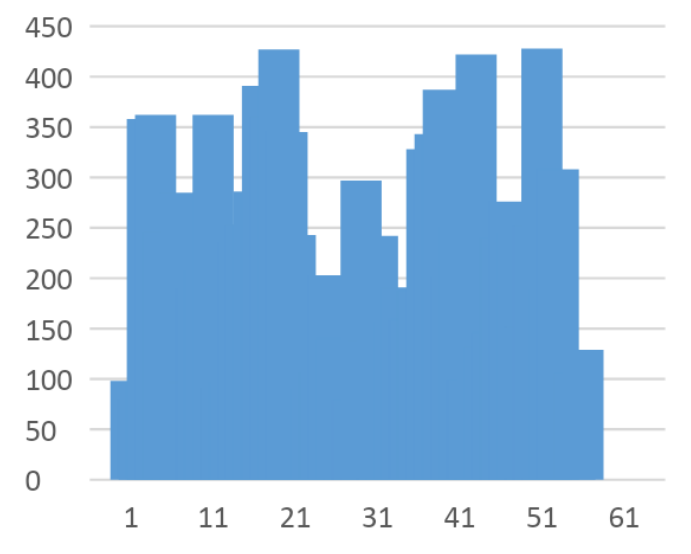

\section{Conclusion}

VAC is an innovative and commercially available concept for the management of difficult to treat wounds and chronic wounds of many aetiologies. It is an effective and inexpensive option to secure better wound healing. The most widely accepted mechanism of action of VAC are enhancement of growth of granulation tissue, increased wound angiogenesis and subsequent improved blood flow. Our study has also found decreased infection rates with the use of VAC. This method of wound treatment needs only short hospital stay.VAC requires fewer dressing changes.VAC has been found to improve graft uptake. Other advantages of VAC include lower rates of hospital acquired infections. Its use has grown to encompass treatment of various types of wounds including acute trauma cases with soft tissue loss. Its popularity lies in its ease- of- application, low 
resource requirement, wide availability, simple technical demands and an inexpensive yet high quality means to achieve better and faster wound healing.

\section{Bibliography}

1. Argenta LC, Morykwas MJ. Vacuumassisted closure: a new method for wound control and treatment: clinical experience. Annals of plastic surgery. 1997 Jun 1:38(6);563-77

2. Mahandaru D, Seswandhana R. The simplest Modified Vacuum Assisted Closure to Treat Chronic Wound: Serial Case report. Jurnal Plastik Rekonstruksi

3. Morykwas MJ. Faler BJ. Pearce DJ, Argenta LC. Effects of varying levels of subatmospheric pressure on the the rate of granulation tissue formation in experimental wound in swine. Annals of plastic surgery .2001 Nov1:47(5): 547-51

4. Weed T, Ratliff C, Drake DB. Quantifying bacterial bioburden during negative pressure wound therapy: does the wound VAC enhance bacterial clearance ? Annals of plastic surgery. 2004 Mar 1:52 (3):2769

5. Wackenfors A. Gustafsson R, Sjogren J, Algotsson L,Ingemansson R, Malmsjo M. Blood flow responses in peristernal thoracic wall during vacuum-assisted closure therapy. The Annals of thoracic surgery 2005 May 31:79(5):1724-30.

6. Timmers MS, Le Cessie S, Banwell P, Jukema GN. The effect of varying degrees of pressure delivered by negative- pressure wound therapy on skin perfusion. Annal of plastic surgery.2005 Dec 1:55 (6):665-71.
7. Kumar P. Exploiting potency of negative pressure in wound dressing using limited access dressing and suction-assisted dressing. Indian journal of plastic surgery: official publication of the Association of Plastic Surgeons of India. 2012 May: 45(2);302

8. Orgill DP, Manders EK, Sumpio BE, Lee RC, Attinger CE, Gurtner GC, Ehrlich HP. The mechanisms of action of vacuumassisted closure: more to learn. Surgery.2009 Jul31:146(1):40-51

9. Borgquist $\mathrm{O}$, Ingemansson R. Malmsjo M. The influence of low and high pressure level during negative pressure wound therapy on wound contraction and fluid evacuation. Plastic and reconstructive surgery.2011 Feb 1:127(2):551-9.

10. Mendez-Eastman S.Guidelines for using negative pressure wound therapy. Advances in skin \&wound care. 2001 Nov1:14(6): 314-23. 